\begin{tabular}{|l|l|l|}
\hline Received: Maret 2021 & Accepted: April 2021 & Published : April 2021 \\
\hline
\end{tabular}

\title{
Alat Pengukur Deviasi pada KWH Meter 3 Fasa berbasis PZEM 0047 dan Flame Sensor
}

\author{
Indra Ferdiansyah $^{1^{*}}$, Epyk Sunarno $^{2}$, Putu Agus Mahadi Putra $^{\mathbf{3}}$, Brilianti Qori' $\mathbf{A}^{\mathbf{4}}$ \\ ${ }^{1 * 2,3,4}$ Politeknik Elektronika Negeri Surabaya \\ *indraferdi@pens.ac.id
}

\begin{abstract}
In the maintenance of Measuring and Limiting Devices (APP) by replacing the $\mathrm{kWh}$ Meter on the old $\mathrm{kWh}$ meter, as well as P2TL efforts to examine customers who have the potential to commit violations or lack of billing in adjusting electricity rates. In this operation an error / deviation check will be performed on the kWh meter to determine the feasibility of the $\mathrm{kWh}$ meter. So far, themeasurement of deviation on the $\mathrm{kWh}$ Meter 3 Phase is done manually so that it is considered less effective. With this deviation gauge kwh meter 3 phase measurement, meter change officers and P2TL field officers will be able to help in measuring the deviation in the 3 phase $\mathrm{kWh}$ meter. This tool reads the power of the kWh meter through the display of the led impulse indicator, then compares it with the power measurement using the metering module at the same time so that the deviation can be detected whether more or less from the meter class, because the measurement standards are based onthe meter class. The results obtained from testing on a kWh meter with a grade of 0.5, obtained a deviation of less than 0.5 percent, which means the $k W h$ meter is good because it is still awake in its class according to SPLN No.96 of 1993.
\end{abstract}

Keywords: Deviation, Kwh Meter, Maintaining APP, P2TL

\begin{abstract}
Abstrak
Dalam upaya pemeliharaan Alat Pengukur dan Pembatas (APP) dilakukan ganti kWh Meter pada kWh meter tua, serta dilakukan juga upaya P2TL untuk memeriksa pelanggan yang berpotensi melakukan pelanggaran atau kurang tagih dalam penyesuaian tarif tenaga listrik. Pada operasi ini akan dilakukan pemeriksaan error/deviasi pada $\mathrm{kWh}$ meter untuk mengetahui kelayakan dari kWh meter tersebut. Selama ini pengukuran deviasi pada kWh Meter 3 Fasa dilakukan secara manual sehingga dinilai kurang efektif. Dengan adanya alat pengukur deviasi pengukuran kwh meter 3 fasa ini petugas ganti meter maupun petugas lapangan P2TL akan dapat terbantu dalam mengukur deviasi pada $\mathrm{kWh}$ meter 3 fasa tersebut. Alat ini membaca daya $\mathrm{kWh}$ meter melalui pembacaan dari indikatorled impulse, kemudian dibandingkan dengan pengukuran daya menggunakan modul metering pada saat yang sama sehingga dapat dideteksi deviasinya apakah lebih atau kurang dari kelas meter tersebut, dikarenakan standard pengukuran didasarkan tertera pada kelas meter. Hasil yang didapat dari pengujian pada sebuah $\mathrm{kWh}$ meter dengan kelas 0.5 , didapatkan deviasi kurang dari 0.5 persen yang berarti $\mathrm{kWh}$ meter tersebut baik karena masih terjaga pada kelasnya sesuai dengan SPLN No.96 Tahun 1993
\end{abstract}

Kata kunci: Deviasi, Kwh Meter, Pemeliharaan APP, P2TL

\section{Pendahuluan}

Dalam upaya pengendalian susut tenaga listrik, PLN memiliki beberapa upaya yakni, pemeliharaan Alat Pengukur dan Pembatas
(APP) serta Penertiban Pemakaian Tenaga Listrik (P2TL) pada pelanggan potensial [1-2]. Dalam upaya pemeliharaan Alat Pengukur dan Pembatas (APP) dilakukan ganti kWh Meter 
pada $\mathrm{kWh}$ meter tua, macet, buram, dan bekas terkena P2TL [1],[3]. Salah satu langkah dalam ganti $\mathrm{kWh}$ meter ini yakni mengukur error/deviasi atau pengukuran daya sesaat, tujuannya agar mengetahui apakah kondisi $\mathrm{kWh}$ meter tersebut masih layak digunakan atau tidak.

Sedangkan, pada upaya P2TL atau Penertiban Pemakaian Tenaga Listrik dalam operasinya sudah disiapkan target operasi pada pelanggan-pelanggan yang berpotensi melakukan pelanggaran atau kurang tagih dalam penyesuaian tarif tenaga listrik. Pada operasi penertiban ini juga dilakukan pengukuran deviasi pada $\mathrm{kWh}$ meter, agar mengetahui apakahada kelainan di $\mathrm{kWh}$ meter tersebut atau tidak [4-5].

Selama ini pengukuran pada kWh Meter 3 Fasa dilakukan dengan clamp on meter atau tang ampere 1 fasa untuk mendapatkan daya aktif perfasa, lalu dijumlahkan manual dengan kalkulator. Kemudian dihitung error/deviasi nya dibandingkan dengan display meter. Hal ini tentu kurang efektif karena dapat membuang banyak waktu, sehingga usulkan alat pengukur deviasi pengukuran $\mathrm{kWh}$ Meter 3 fasa dengan membandingkan daya dari hasil pengukuran melalui PZEM Sensor yang telah terkalibrasi dan pengukuran daya dengan kedipan pada impulse $\mathrm{kWh}$ meter digital dengan memanfaatkan prinsip kerja dari Flame Sensor sebagai deteksi titik cahaya. Hal ini dilakukana guna untuk memudahkan petugas ganti meter ataupun P2TL dalam menjalankan tugasnya sehingga lebih efektif dan efisien.

\section{Metoda Penelitian}

\subsection{KWH Meter}

Alat Pengukur dan Pembatas Listrik (APP) merupakan alat yang digunakan untuk mengukur dan membatasi pemakaian listrik dari pelanggan. Alat pengukur yang digunakan pada pelanggan yakni $\mathrm{kWh}$ meter sedangkan untuk alat pembatas yakni berupa MCB (Mini Circuit Breaker). KWh Meter mengukur daya dengan waktu tertentu yang kemudian disebut energy. Pemakaian energy listrik oleh pelanggan menggunakan satuan $\mathrm{kWh}$ (Kilo Watt Hour). Berikut detail dari fungsi KWH Meter [6-8]:

1. Pembatas daya yang digunakan oleh pelanggan (sesuai dengan kontrakpemasangan)

2. Mencatat daya yang dipakai oleh konsumen. Karena itu ada yang menyebutnya "kWh Meter" atau "Meteran Listrik" $(\mathrm{kWh}=$ kilowatt hour)

3. Saklar utama pemutus aliran listrik bila terjadi kelebihan pemakaian daya oleh pelanggan, adanya gangguan hubung singkat dalam instalasi listrik rumah pelanggan atau sengaja dimatikan untuk keperluan perbaikan instalasi listrik rumah.

Sedangkan untuk jenis $\mathrm{kWh}$ meter terdapat 2 jenis, yakni $\mathrm{kWh}$ meter analog dan digital. Keduanya menggunakan prinsip yang sama akan tetapi jika $\mathrm{kWh}$ meter analog menggunakan piringan, sedangkan $\mathrm{kWh}$ meter digital sudah menggunakan LED impulse. Bentuk fisik dari jenis KWH meter tersebut ditampilkan pada gambar 1 .

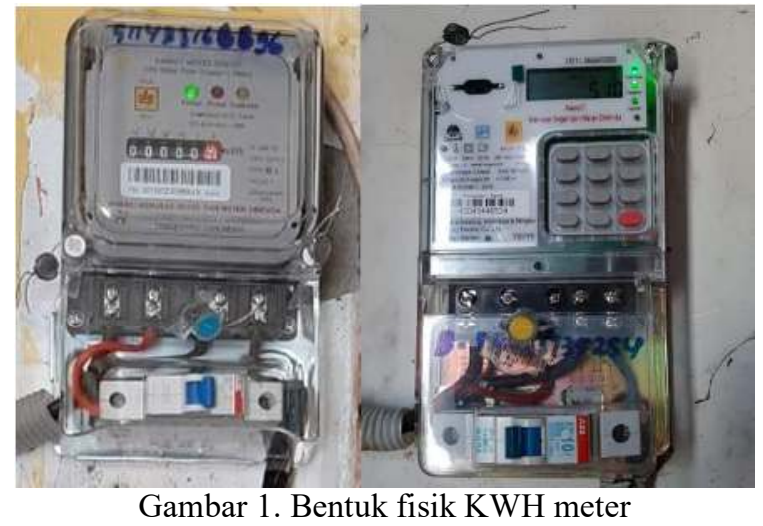

Cara kerja $\mathrm{kWh}$ meter digital secara umum terdiri dari 3 tahap, yaitu:

1. Mendeteksi tegangan dan arus sesaat.

2. Mengalikan kedua besaran (tegangan dan arus) untuk memperoleh daya sesaat.

3. Mengintegrasikan/mengakumulasi hasil perkalian tegangan dan arus pada poin 2 . 
Detail blok diagram dari KWH meter digital ditampilkan pada gambar 2 .

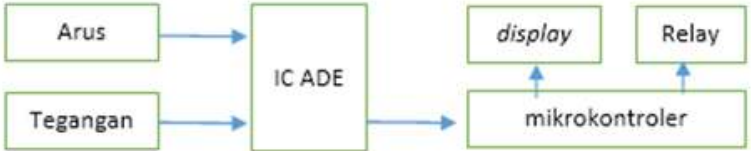

Gambar 2. Blok sistem KWH meter digital

\subsection{Deviasi KWH Meter}

Pengukuran daya pada $\mathrm{kWh}$ meter digital tidak lagi menggunakan piringan, melainkan menggunakan impulse atau dengan menghitung nyala LED pada $\mathrm{kWh}$ meter tersebut, biasanya setiap $\mathrm{kWh}$ meter mempunyai konstanta impulse yang berbeda. Tergantung dari merk maupun produsen yang membuat meter tersebut. KWh meter menghitung jumlah energi yang mengalir tidak saja pada pembebanan konstan, tetapi juga pada pembebanan yang berubah. Untuk menentukan benar tidaknya penunjukan $\mathrm{kWh}$ meter, maka $\mathrm{kWh}$ meter dioperasikan pada pembebanan yang tertentu dan mengukur besarnya daya yang mengalir serta mengamati $\mathrm{kWh}$ meter yang sedang di test. Oleh karena itu perlu dilakukannya pengukuran deviasi atau penyimpangan antara pengukuran $\mathrm{kWh}$ meter dengan daya yang digunakan oleh pelanggan. Adapun rumus untuk mencari nilai deviasi $\mathrm{kWh}$ meter dengan membandingkan daya yang terukur pada $\mathrm{kWh}$ meter tersebut dengan alat pembanding yang juga mengukur daya. Deviasi dari $\mathrm{kWh}$ meter 3 fasa dapat dihitung dengan cara sebagai berikut [5-7], [9$10]$ :

$P 1=\frac{3600000 \times n}{t \times c} \times 100(W)$

$P 2=P r+P s+P t(W)$

Sehingga kesalahan kWh Meter dapat dihitung:

$\%$ error $=\frac{P 1-P 2}{P 2} \times 100 \%$

Dimana:

Pr: Hasil pengukuran daya pada fasa R (W)
Ps: Hasil pengukuran daya pada fasa $\mathrm{S}(\mathrm{W})$

Pt: Hasil pengukuran daya pada fasa T (W)

P1: Daya berdasarkan pembacaan dari led indicator impulse $\mathrm{kWh}$ meter $(\mathrm{W})$

P2: Daya yang terukur hasil pengukuran (W)

$\mathrm{n}$ : Jumlah kedipan led indicator impulse

t: Waktu yang diperlukan untuk mencapai jumlah $\mathrm{n}$ kedipan(detik)

c: Konstanta impulse $\mathrm{kWh}$ meter (imp/kWh)

\%error: Kesalahan baca meter atau deviasi pada $\mathrm{kWh}$ meter

Standard deviasi dari $\mathrm{kWh}$ meter diatur pada SPLN No.96 tahun 1993. Dalam standard ini batas-batas kesalahan presentase yang diizinkan disesuaikan dengan kelas daripada $\mathrm{kWh}$ meter sendiri [10-12], berikut detail table nilai deviasi yang diizinkan:

Tabel 1.Batas kesalahan yang diizinkan sesuai SPLN No.9 tahnu 1993 pada KWH meter kelas 0.5

\begin{tabular}{|c|c|c|c|}
\hline Kelas & \multicolumn{3}{|c|}{0.5} \\
\hline Faktor Daya & 1 & 05 & 05 \\
\hline Error max & \pm 0.10 & $\begin{array}{c}\text { lagging } \\
\pm 0.15\end{array}$ & $\begin{array}{c}\text { leading } \\
\pm 0.20\end{array}$ \\
\hline
\end{tabular}

Tabel 2.Batas kesalahan yang diizinkan sesuai SPLN No.9 tahnu 1993 pada KWH meter kelas 1

\begin{tabular}{cccc}
\hline $\begin{array}{c}\text { Kelas } \\
\text { Meter }\end{array}$ & \multicolumn{3}{c}{$\mathbf{0 . 5}$} \\
\hline Faktor Daya & 1 & 0.5 & 0.5 \\
& & $\begin{array}{c}\text { lagging } \\
\pm 0.30\end{array}$ & $\begin{array}{c}\text { leading } \\
\pm 0.40\end{array}$ \\
Error max & \pm 0.20 & \pm 0.
\end{tabular}

Tabel 3.Batas kesalahan yang diizinkan sesuai SPLN No.9 tahnu 1993 pada KWH meter kelas 2

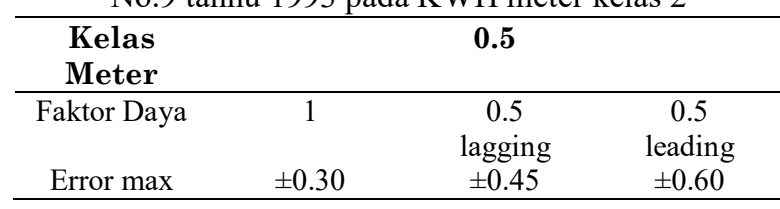

\subsection{Modul Metering PZEM 0047}

Modul ini dapat digunakan mengukur tegangan, arus, cos phi, dan energi. Dimensi fisik papan PZEM-004T adalah 3,1 × 7,4 cm dan modul ini sudah dilengkapi sensor tegangan dan sensor arus berupa CT (Current Transformer). Pengkabelan modul ini dibagi menjadi dua bagian yakni AC port yang 
berisikan terminal tegangan dan arus dari sumber AC, dan TTL port sebagai kabel komunikasi serial.

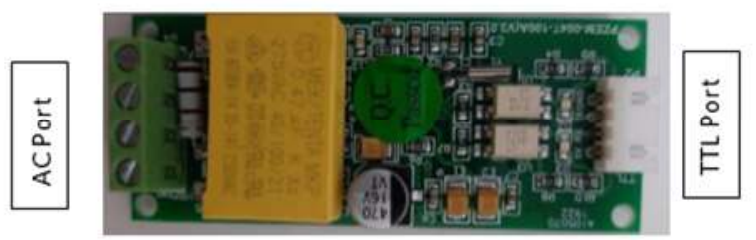

Gambar 3. Bentuk fisik PZEM 004T

Pada 3 menunjukan bentuk fisik dari modul PZEM-004T, dan bagian utama dari modul ini adalah chip SD3004 dari SDIC Microelectronics Co., Ltd. Selain itu, modul ini memiliki EEPROM dari Atmel 24C02C yang merupakan $2 \mathrm{~K}$ bit Serial PROM dan menggunakan tegangan input $5 \mathrm{~V}$. Spesifikasi dari modul PZEM 004T yang digunakan adalah sebagai berikut:

1. Tegangan kerja : 80-260 VAC

2. Nilai daya $: 100 \mathrm{~A} / 22000 \mathrm{~W}$

3. Akurasi Pengukuran : 1.0 grade

4. Frekuensi pengoperasian : $45-65 \mathrm{~Hz}$

\subsection{Modul Flame Sensor}

Modul ini digunakan untuk menangkap impulse dari $\mathrm{kWh}$ meter digital, kemampuan penangkapan cahaya infrared oleh modul ini dimanfaatkan untuk pembacaan LED dari $\mathrm{kWh}$ meter yang berwarna merah. Berikut detail spesifikasi Flame Sensor yang digunakan pada sistem yang diusulkan. Bentuk fisik Flame Sensor ditampilkan pada gambar 4.

1. Sensitif dalam penerimaan infrared

2. Sensitivitas dari gelombang antara 760 hingga $1100 \mathrm{Nm}$

3. Dilengkapi lampu indicator untuk power supply

4. Dilengkapi dengan indicator pendeteksi sinar inframerah

5. Output digital berupa 0 dan 1

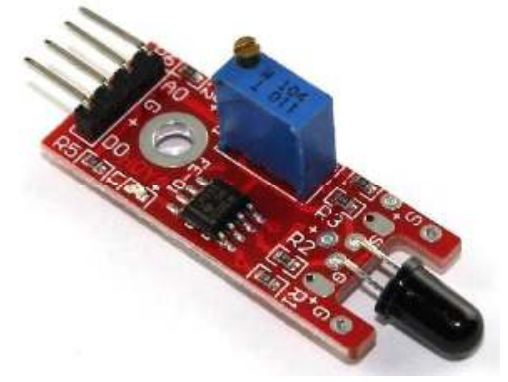

Gambar 4. Bentuk fisik Flame Sensor

Pada sistem yang diusulkan manggunakan sensor Flame, dimana fungsi dari sensor atau modul ini yaitu untuk mendeteksi adanya sumber cahaya (Api). Dalam hal ini sensor akan digunakan untuk mendeteksi adanya sumber cahaya, yaitu kedip lampu led yang ada pada KWH meter kemudian di counting untuk melakukan perhitungan daya seperti yang dijelaskan pada persamaan 1

\section{Hasil Penelitian}

\subsection{Pengujian Sistem Secara Parsial}

Sistem yang dibuat bertujuan untuk melakukan pembacaan daya pada $\mathrm{kWh}$ meter digital 3 fasa dari led indikator impulse $\mathrm{kWh}$ meter tersebut dengan menggunakan modul sensor penangkap cahaya, kemudian didapatkan hasil pengukuran daya melalui jumlah impulse kedipan led indicator impulse. Daya yang telah terkur tersebut dibandingkan dengan daya yang diukur dengan modul metering PZEM 004T, kemudian akan didapatkan hasil perbandingannya serta akan terlihat error pengukuran atau deviasi dari $\mathrm{kWh}$ meter digital 3 fasa tersebut. Modul metering PZEM 004T diasumsikan sebagai alat kalibrator dari $\mathrm{kWh}$ meter.

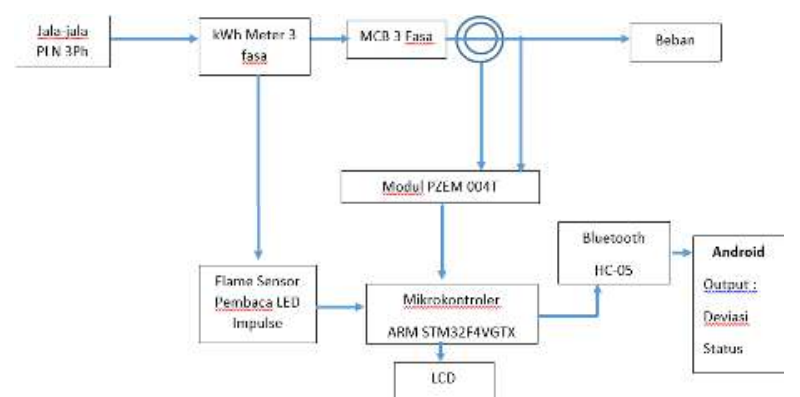

Gambar 5. Blok Pengujian Sistem 
Berdasarkan Gambar 5 secara umum prinsip kerja dari blok diagram tersebut yakni pada $\mathrm{kWh}$ meter digital 3 fasa dipasang sensor untuk membaca led indicator impulse yang kemudian akan mengaukumulasikan daya dengan otomatis membaca selama 1 menit setelah penangkapan led pertama dibaca sensor. Di sisi lain modul metering digunakan untuk mengukur daya sebagai pembanding dengan arus diambil dari sumber sebelum masuk ke beban dengan menggunakan current transformer dan tegangan dari jala-jala listrik terdekat. Pengujian menggunakan meter test bench. Daya yang terukur dengan modul PZEM 004T masuk kedalam mikrokontroler dan diproses untuk dibandingkan dengan daya yang dihasilkan oleh pembacaan led indicator impulse untuk didapatkan besar error atau nilai deviasi yang dihasilkan $\mathrm{kWh}$ meter digital 3 fasa tersebut. Perancangan modul pengujian ini berupa box yang didalamnya terdapat mikrokontroller ARM STM32F407 Discovery, 3 modul PZEM 004T, dan modul Bluetooth $\mathrm{HC}-05$. Sedangkan untuk flame sensor yang difungsikan sebagai sensor penangkap led impulse dari $\mathrm{kWh}$ meter diberikan box tersendiri yang berwarna hitam agar tidak terganggu cahaya dari luar.

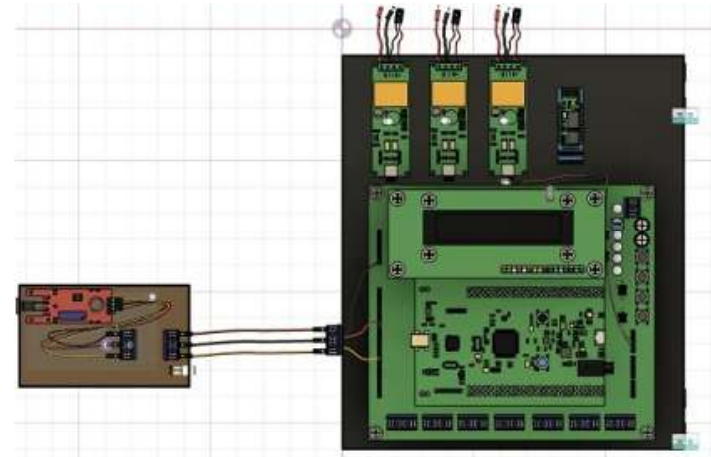

Gambar 6. Perencanaan Modul Pengujian

Pada Gambar 6 merupakan desain modul pengujian, pada perancangan ini modul pengujian menggunakan akrilik yang dibentuk box kotak dengan engsel di samping kanan. Modul pengujian ini didalamnya terdapat mikrokontroler ARM STM32F4, 3 buah modul PZEM 004T, dan juga modul Bluetooth HC05. Modul PZEM 004T di urutkan berdasarkan fasanya, mulai dari fasa $\mathrm{R}, \mathrm{S}$, dan $\mathrm{T}$. Kemudian pada sisi atas box, terdapat lubang yang digunakan sebagai keluaran kabel daripada PZEM 004T.

Berikut Program counter kedipan led digunakan untuk menghitung banyak impulse selama 1 menit disesuaikan dengan rumus yang ada pada sensor Flame. Program yang digunakan menggunakan keil uVision 5 karena mikrokontroller yang digunakan yakni ARM STM32F4 Discovery. Pada pemrograman ini counter dimulai sejak penangkapan led impulse pertama.

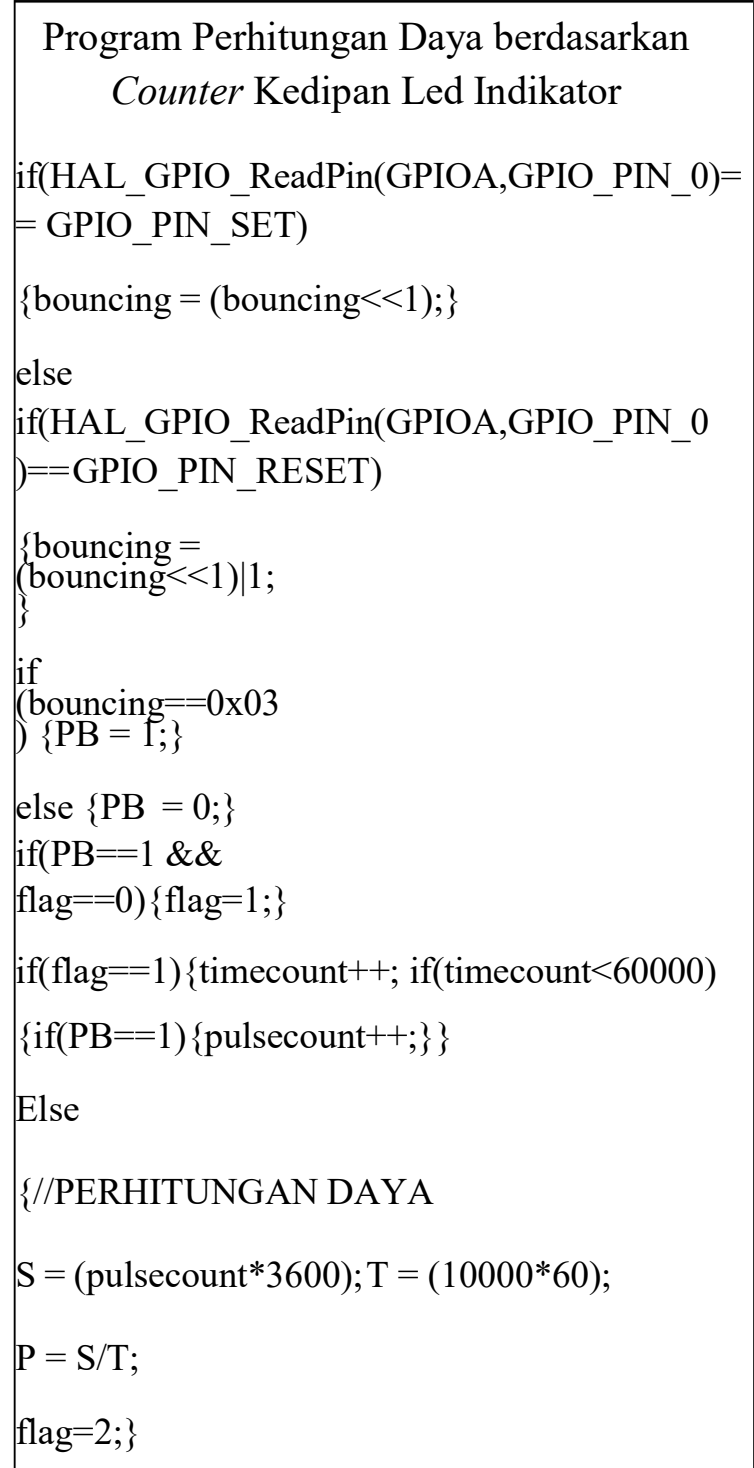


Hasil pengujian flame sensor dan modul PZEM dibandingkan dengan pembacaan masing-masing alat ukur sebagai kalibrasi. Pembacaan daya pada Flame sensor dibandingkan dengan pembacaan daya pada display $\mathrm{KwH}$ meter digital, sedangkan untuk pembacaan daya menggunakan modul PZEM dibandingkan dengan Clam on meter. Detail hasil pengujian ditampilkan sebagai berikut:

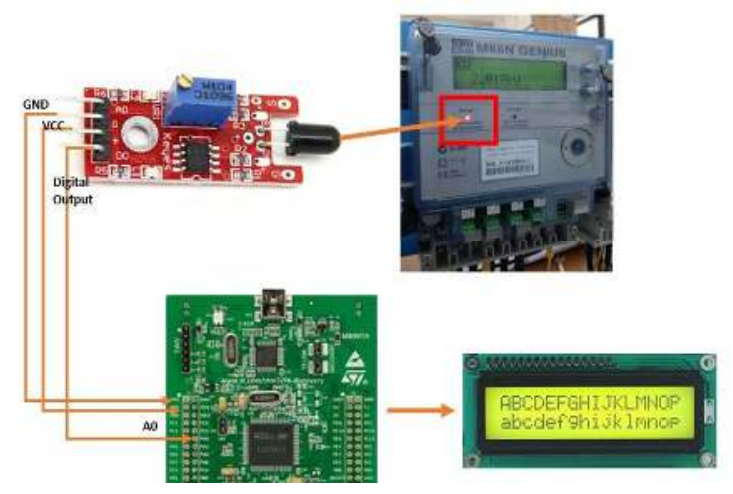

Gambar 7. Konfigurasi pengujian Flame Sensor

Tabel 4. Data hasil pengujian Flame Sensor

\begin{tabular}{ccccc}
\hline No. & $\begin{array}{c}\text { Arus } \\
\text { (A) }\end{array}$ & $\begin{array}{c}\text { Pembacaan } \\
\text { Daya sensor } \\
(\mathbf{k W})\end{array}$ & $\begin{array}{c}\text { Pembacaan } \\
\text { Daya KWH } \\
\text { Meter }(\mathbf{k W})\end{array}$ & $\begin{array}{c}\text { Error } \\
\mathbf{( \% )}\end{array}$ \\
\hline 1 & 1 & 0.67 & 0.69 & 2.8 \\
2 & 1.5 & 0.98 & 0.99 & 1.01 \\
3 & 2 & 1.35 & 1.36 & 0.7 \\
4 & 2.5 & 1.59 & 1.61 & 1.24 \\
\hline
\end{tabular}

Berdasarkan data pada Tabel 4 dapat dilihat bahwa saat dilakukan pengukuran daya menggunakan led indikator impulse, selisih dari pengukuran tersebut dengan daya yang ditampilkan pada display $\mathrm{kWh}$ meter tidak terlalu jauh. Saat dibebani dengan arus 1A, daya yang terukur berdasarkan pembacaan flame sensor sebesar $0.67 \mathrm{~kW}$, sedangkan daya berdasarkan display sebesar $0.69 \mathrm{~kW}$, sehingga selisihnya sebesar $0.002 \mathrm{~kW}$. Untuk selisish paling jauh terjadi saat sistem dibebani $2.5 \mathrm{~A}$ dengan selisih sebesar $0.003 \mathrm{~kW}$. Berdasarkan hasil pengujian yang telah dilakukan penggunaan Flame sensor sebagai penghitung daya dengan membaca impulse atau cahaya kedip pada $\mathrm{kWh}$ meter memiliki efektifitas yang tinggi. Hal tersebut dapat dilihat dari nilai error pembacaan dayanya dibawah $3 \%$.
Selanjutnya dilakukan pengujian pada sensor daya menggunakan PZEM 004T, pengujian dilakukan dengan memberikan beban 4 buah lampu pijar yang masing-masing memiliki daya sebesar 100 watt, kemudian $\mathrm{n}$ hasil pengukuran modul metering PZEM 004T dibandingkan dengan clamp on meter. Konfigurasi pengujian PZEM 004T dapat dilihat pada Gambar 8.

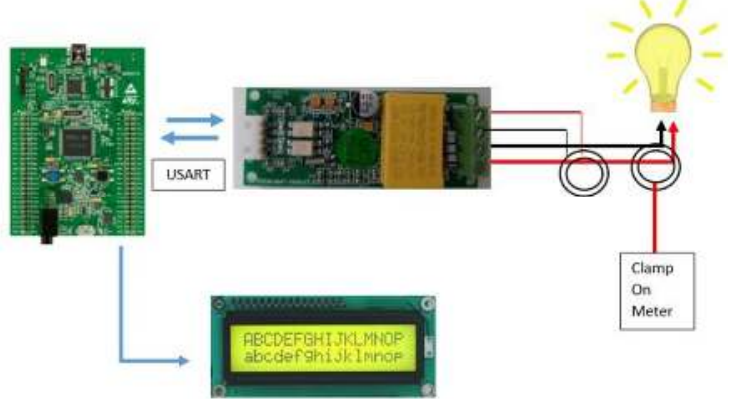

Gambar 8. Konfigurasi pengujian PZEM 004T

Tabel 5. Data hasil pengujian PZEM004T

\begin{tabular}{ccccc}
\hline No. & Beban & $\begin{array}{c}\text { Pembacaan } \\
\text { Daya sensor } \\
\text { PZEM(kW) }\end{array}$ & $\begin{array}{c}\text { Pembacaan } \\
\text { Daya } \\
\text { Clamp } \\
\text { Meter (kW) }\end{array}$ & $\begin{array}{c}\text { Error } \\
\mathbf{( \% )}\end{array}$ \\
\hline 1 & 1 lampu & 0.0971 & 0.097 & 0.1 \\
2 & 2 lampu & 0.1923 & 0.193 & 0.36 \\
3 & 3 lampu & 0.2906 & 0.291 & 0.14 \\
4 & 4 lampu & 0.3847 & 0.387 & 0.59 \\
\hline
\end{tabular}

Berdasarkan Tabel 5, dapat dilihat saat dibebani 1 lampu sebesar $100 \mathrm{~W}$, pengukuran Clamp Meter sebesar $0.097 \mathrm{~kW}$, sedangkan pengukuran PZEM 004T sebesar $0.0971 \mathrm{~kW}$, sehingga error dari pengujian ini yakni sebesar $0.1 \%$, error terbesar berada di beban 4 lampu dengan pengukuran tang ampere sebesar 0.387 $\mathrm{kW}$ sedangkan untuk pengukuran sensor daya PZEM 004T sebesar $0.3847 \mathrm{~kW}$, sehingga didapatakan error sebesar $0.59 \%$. Dari hasil pengukuan diatas dapat dilihat sensor PZEM dapat melakukan pengukurang dengan baik, dimana modul yang dirancang dapat melakukan pembacaan daya yang akurat dan efektif yaitu dengan cara melakukakn identifikasi besar nilai arus dan tegangan kemudian dikonversikan menjadi besaran daya. Dari hasil percobaan yang dilakukan didapatkan nilai error pembacaan dayanya dibawah 1\% 


\subsection{Pengujian Integrasi $\quad$ Sistem \\ Keseluruhan}

Pengujian ini bertujuan untuk mengetahui apakah sistem yang telah dirancang dan dibuat telah bekerja dengan baik sesuai yang telah direncanakan di awal. Mulai dari fungsi pengukuran daya oleh counter dari flame sensor, pengukuran daya dari PZEM 004T, pengukuran deviasi dan keterangan dari $\mathrm{kWh}$ meter yang merupakan perbandingan dari deviasi dengan kelas meter. Dalam pengujian ini menggunakan meja tera yang akan mensupply tegangan maupun arus sebagai beban sesuai pada gambar 9. Dengan menggunakan meja tera system dapat diuji dengan beberapa variable arus yaitu pada range arus 4-6A. Detail konfigurasi pengujian dan integrasi beserta hasilnya ditampilkan pada gambar 10 .

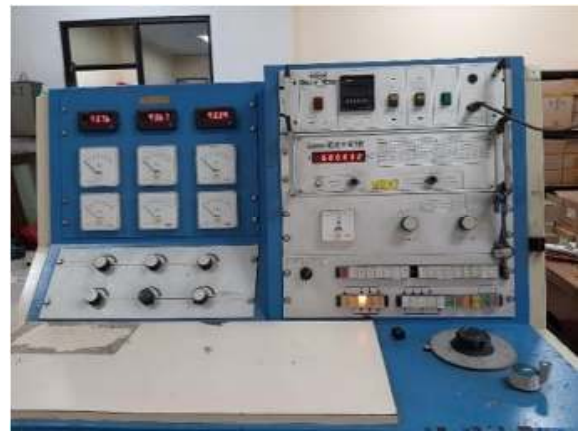

Gambar 9. Meja Tera Schlumberger

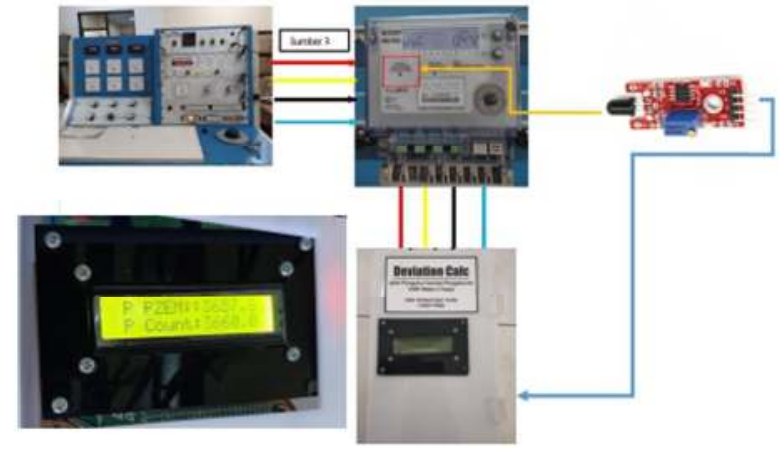

Gambar 10. Konfigurasi pengujian integrasi

Gambar 10 merupakan pengujian integrasi, langkah yang pertama dilakukan yakni menyambungkan mikrokontroler dengan powerbank sebagai sumber catu daya untuk mikrokontroler, kemudian menyambungkan kabel keluaran dari PZEM 004T untuk sensing tegangan pada masing-masing fasa kemudian untuk flame sensor yang difungsikan sebagai penangkap led impulse dari $\mathrm{kWh}$ meter di posisikan didepan lampu led impulse agar penangkapan cahaya kedipan maksimal dan dilakukan selama 1 menit. Mikrokontroler akan mengubah data counter menjadi daya dan akan menampilkan data tersebut pada LCD. P PZEM diatas adalah total daya dari ketiga PZEM yang sudah disambungkan pada masing-masing fasa. Sedangkan untuk P Count adalah daya dari perhitungan led impulse selama 1 menit yang ditangkap oleh flame sensor. Data yang didapatkan pada arus di fasa $\mathrm{R}=5.553, \mathrm{~S}=5.605, \mathrm{~T}=5.495$, daya yang terukur dengan flame sensor (P1) sebesar 3660, dan pada pengukuran PZEM (P2) sebesar 3640. Sehingga, deviasi kWh Meter sebesar 0.5, hal ini didapatkan dari perhitungan sesuain dengan persamaan 3. Pengujian dilakukan dengan memeberikan beban variable untuk melihat kinerja dari sistem untuk menetukan deviasi pengukuran pada KWH meter 3 fasa, detail hasil pengukuran deviasi ditampilkan pada table 6 .

Tabel 6. Data pengujian sistem secara keseluruhan

\begin{tabular}{|c|c|c|c|c|c|c|}
\hline $\begin{array}{l}\mathrm{N} \\
\mathrm{O}\end{array}$ & $\begin{array}{c}\text { Arus } \\
\text { 'R' } \\
\text { (A) }\end{array}$ & $\begin{array}{c}\text { Arus } \\
\text { 'S' } \\
\text { (A) }\end{array}$ & $\begin{array}{l}\text { Arus } \\
\text { 'T' } \\
\text { (A) }\end{array}$ & $\begin{array}{c}\text { P1 } \\
\text { (W) }\end{array}$ & $\begin{array}{c}\text { P2 } \\
\text { (W) }\end{array}$ & $\begin{array}{c}\text { Deviasi } \\
(\%)\end{array}$ \\
\hline 1 & 4.05 & 4.03 & 4.21 & 2700 & 2684 & 0.5 \\
\hline 2 & 4.43 & 4.85 & 4.52 & 3000 & 3013 & 0.4 \\
\hline 3 & 5.18 & 4.95 & 5.24 & 3360 & 3363 & 0.1 \\
\hline 4 & 5.58 & 5.62 & 5.51 & 3660 & 3654 & 0.1 \\
\hline 5 & 6.35 & 6.09 & 6.03 & 4080 & 4060 & 0.4 \\
\hline
\end{tabular}

Dengan menggunakan meja tera arus pengujian dapat diubah-ubah sesuai dengan rencana awal, yakni pada range 4-6A, akan tetapi sulit untuk mendapatkan step 0,5 karena untuk selector pemilihan arus seperti variac atau potensio sehingga sulit ketika digunakan untuk mendapatkan nilai arus yang sesuai step kenaikan 0.5. Sehingga pengujian sistem dilakukan dengan variable arus seperti pada tabel 6. Berdasarkan hasil pengujian, saat diberikan arus sebesar rata-rata 4 ampere pada masing-masing fasa, pengukuran daya dengan flame sensor sebesar $2700 \mathrm{~W}$, sedangkan pengukuran PZEM 004T sebesar 2684.5W 
sehingga menghasilkan deviasi sebesar $0.5 \%$. Kemudian saat dibebani dengan arus 4,5 ampere deviasi sebesar $0.4 \%$, dan saat dibebani 5 ampere pengukuran deviasi sebesar $0.1 \%$. Dengan demikian dapat diketahui bahwa pengukuran deviasi dapat berubah-ubah pada case beban yang berbeda, hal ini dikarenakan sumber tegangan yang tidak statis. Sehingga dapat disimpulkan bahwa hasil deviasi yang didapat dari pengujian $\mathrm{kWh}$ Meter 3 Fasa merk EDMI tipe Mk10E buatan tahun 2015 dengan kelas 0.5 yakni masih dibawah 0.5 persen sehingga $\mathrm{kWh}$ meter tersebut dikatan dalam kondisi baik karena masih terjaga pada kelasnya. Hal ini sesuai dengan SPLN No.96 tahun 1993 mengenai batas-batas kesalahan presentase yang diizinkan berdasarkan kelas meter.

\section{Kesimpulan}

Kerja dari flame sensor pada saat digunakan untuk mengukur daya berdasarkan kedipan cahaya pada KWH meter Impulse sangat baik, sensor tersebut dapat menangkap kedipan led sesuai dengan aslinya. Sesuai dengan prinsip kerja dari alat tersebut yaitu untuk mendeteksi sumber cahaya. Namun, Flame sensor terlalu peka terhadap cahaya sehingga pemsangan sensor harus dilakukan pada jarak yang dekat dengan pada lampu led impulse KWH meter. Hasil yang didapatkan dari pembacaan sensor yaitu hanya memiliki nilai error kurang dari 3\% jika dibandingkan dengan pembacaan pada display KWH meter. Selanjutnya penggunan modul sensor PZEM 0047 juga memiliki performa yang baik karena jika hasil pengukuranya dibandingkan dengan clamp on meter memiliki nilai error dibawah $1 \%$. Sehingga metode pengukuran deviasi yang di usulkan dapat digunakan untuk pemeriksaan kelayakan dari APP, seperti halnya pengujian yang dilakukakan pada $\mathrm{kWh}$ Meter 3 Fasa merk EDMI tipe Mk10E buatan tahun 2015 dengan kelas 0.5 yakni masih dibawah 0.5 persen, maka dapat dikatakan KWH meter tersebut dalam kondisi baik.

\section{Saran}

Dalam penggunaan modul PZEM 004T dapat digunakan CT agar dapat digunakan untuk pelanggan TM, sehingga arus yang masuk pada PZEM 004T tidak melebihi range. Serta Menambahkan fitur pengisian konstanta dari $\mathrm{kWh}$ meter, agar alat ini dapat digunakan pada semua jenis $\mathrm{kWh}$ meter 3 fasa dan tidak terbatas pada $\mathrm{kWh}$ meter dengan konstanta $1000 \mathrm{impulse} / \mathrm{kWh}$.

\section{Daftar Pustaka}

[1] Fakhri Ramdana, Muhammad Nasrun, Casi Setianingsih, Muhammad Ary Murti, "Prototype Design Mapping of $\mathrm{kWh}$ Meters Based on Internet of Things (IoT)," in 4th International Conference on Advanced Mechatronics, Intelligent Manufacture, and Industrial Automation, Batu, Indonesia, 2019.

[2] Gunawan Wibisono, Euis Suryati, " Machine to machine application as KWh meter controlling," in International Conference on Quality in Research (QiR) : International Symposium on Electrical and Computer Engineering, Nusa Dua, Indonesia, 2017.

[3] Marina Artiyasa, Siti Neni Hanifah, Ahmad Felani, "Analysis deviation of direct measurement KWh meter in PLN P2TL Rayon Sukaraja Kab. Sukabumi," in International Conference on Computing, Engineering, and Design (ICCED), Kuala Lumpur, Malaysia, 2017.

[4] Fakhri Ramdana, Muhammad Nasrun, Casi Setianingsih, Muhammad Ary Murti, "Prototype Design Mapping of $\mathrm{kWh}$ Meters Based on Internet of Things (IoT)," in 2019 International Conference on Advanced Mechatronics, Intelligent Manufacture and Industrial Automation (ICAMIMIA), Batu, Indonesia, 2019.

Muliadi, M. Yogi Fahrezi, Intan Sari Areni, Elyas Palantei, Andani Achmad," 
[5] A Smart Home Energy Consumption Monitoring System Integrated with Internet Connection," in 2020 IEEE International Conference on Communication, Networks and Satellite (Comnetsat), Batam, Indonesia, 2020.

[6] Ruengwit Khwanrit, Somsak Kittipiyakul, Jasada Kudtonagngam, Hideaki Fujita, " Accuracy Comparison of Present Lowcost Current Sensors for Building Energy Monitoring," in 2018 International Conference on Embedded Systems and Intelligent Technology \& International Conference on Information and Communication Technology for Embedded Systems (ICESIT-ICICTES), Khon Kaen, Thailand, 2018.

[7] Herryawan Pujiharsono, Hanung Adi Nugroho, Oyas Wahyunggoro, " The stand meter extraction of kWh-meter," in International Conference on Science in Information Technology (ICSITech), Yogyakarta, Indonesia, 2015.

[8] Enokela. J .A, "A Comparison of Performances of Electronic and Electromechanical Energy Meter," Nigerian Journal of Technology, vol. 26, no.2, PP. 56-62, 2007.
[9] Suhantono, Djoko dkk, "Evaluasi Error KWh Meter Analog Pengukuran Langsung dengan Metode Peneraan Waktu Pada Laboratorium Jurusan Teknik Elektro Politeknik Negeri Bali," Jurnal Matrix, vol. 8, no.1, PP. 16-21, 2007.

[10] Shujiang, Duo dkk, "Analysis and Suggestions on Measurement Error of Electric Energy Meter," Advances in Engineering Research, vol. 152, pp. 388390, 2018.

[11] Suci Rahmatia, Samudra, Boy Iswandii, " Design monitoring system $\mathrm{kWh}$ meter 3 phase using RFID system: PT. Multifabrindo Gemilang," in International Conference on ICT for Smart Society, Jakarta, Indonesia, 2013.

[12] Hilwadi Hindersah, Agus Purwadi, Farianza Yahya Ali, Nana Heryana, "Prototype development of single phase prepaid kWh meter," in Proceedings of the 2011 International Conference on Electrical Engineering and Informatics, Bandung, Indonesia, 2011.

[13] SPLN No.96 tahun 1993 Tentang Perlengkapan Uji Untuk Meter Energi Listrik, $(96,3)$. 